\title{
How Do Religiosity and National Identity Relate to Cosmopolitanism? An Empirical Study Using Representative Samples in Christian, Muslim, and Buddhist Societies
}

\author{
James H. Liu, Robert Jiqi Zhang, Huajian Cai, Silvia Mari, Xiaoyan Qu and \\ Ahmet Suerdam
}

\section{QUERY SHEET}

This page lists questions we have about your paper. The numbers displayed at left are hyperlinked to the location of the query in your paper.

The title and author names are listed on this sheet as they will be published, both on your paper and on the Table of Contents. Please review and ensure the information is correct and advise us if any changes need to be made. In addition, please review your paper as a whole for typographical and essential corrections.

Your PDF proof has been enabled so that you can comment on the proof directly using Adobe Acrobat. For further information on marking corrections using Acrobat, please visit http://journalauthors.tandf.co.uk/production/acrobat.asp; https://authorservices.taylorandfrancis.com/how-to-correct-proofs-with-adobe/

The CrossRef database (www.crossref.org/) has been used to validate the references. Changes resulting from mismatches are tracked in red font.

\section{AUTHOR QUERIES}

Q1 Please check the author sequences and their surnames has set correctly.

Q2 Please provide missing Department for all the affiliations.

Q3 The funding information “Asian Office of Aerospace Research and Development” and "FA2386-15-1-0003" provided has been checked against the Open Funder Registry and we failed to find a match. Please confirm if the Funding section is accurate and also confirm the funder name "Asian Office of Aerospace Research and Development" and "FA2386-15-10003".

Q4 The reference "Appiah, 2005" is cited in the text but is not listed in the references list. Please either delete in-text citation or provide full reference details following journal style [APA-7]

Q5 The year for "Cleveland et al., 2007" has been changed to 2009 to match the entry in the references list. Please provide revisions if this is incorrect.

Q6 The year for "McFarland, 2018" has been changed to 2017 to match the entry in the references list. Please provide revisions if this is incorrect.

Q7 The reference "Smith (2003)" is cited in the text but is not listed in the references list. Please either delete in-text citation or provide full reference details following journal style [APA-7]

Q8 The reference "Citrin et al., 1990" is cited in the text but is not listed in the references list. Please either delete in-text citation or provide full reference details following journal style [APA-7] 
Q9 The reference "Huddy \& Khatib, 2007" is cited in the text but is not listed in the references list. Please either delete in-text citation or provide full reference details following journal style [APA-7]

Q10 The reference "Postmes et al., 2012" is cited in the text but is not listed in the references list. Please either delete in-text citation or provide full reference details following journal style [APA-7]

Q11 The disclosure statement has been inserted. Please correct if this is inaccurate.

Q12 The PubMed (http://www.ncbi.nlm.nih.gov/pubmed) and CrossRef (www.crossref.org/) databases have been used to validate the references. Mismatches between the original manuscript and PubMed or CrossRef are tracked in red font. Please provide a revision if the change is incorrect. Do not comment on correct changes.

Q13 The Reference "Bielefeldt, 1995" is listed in the references list but is not cited in the text. Please either cite the reference or remove it from the references list.

Q14 The Reference "Ibrahim, 1990" is listed in the references list but is not cited in the text. Please either cite the reference or remove it from the references list.

Q15 Please provide missing DOI or URL, if available, for the "Jaspers, 1948" references list entry.

Q16 Please provide missing Issue for the "Jaspers, 1948” references list entry.

Q17 Please provide missing DOI or URL, if available, for the "Kaplan, 2009” references list entry.

Q18 Please provide missing Issue for the "Kaplan, 2009” references list entry.

Q19 Please provide missing Issue/page number/volume number for the "Khan et al., 2019" references list entry.

Q20 The Reference "Khan et al., 2019" is listed in the references list but is not cited in the text. Please either cite the reference or remove it from the references list.

Q21 Please provide missing Issue for the "Leung et al., 2015" references list entry.

Q22 The Reference "Price, 2002" is listed in the references list but is not cited in the text. Please either cite the reference or remove it from the references list.

Q23 Please provide missing Issue for the "Richerson et al., 2016" references list entry.

Q24 Please provide missing Issue/volume number for the "Schumann et al., 2019" references list entry.

Q25 The Reference “Stark, 1997" is listed in the references list but is not cited in the text. Please either cite the reference or remove it from the references list.

Q26 Please provide missing Publisher name for the “UNDP, 2015” references list entry.

Q27 Please provide missing DOI or URL, if available, for the "Wiktor et al., under review" references list entry.

Q28 Please provide missing Issue/page number/volume number for the "Wiktor et al., under review" references list entry. 


\title{
How Do Religiosity and National Identity Relate to Cosmopolitanism? An Empirical Study Using Representative Samples in Christian, Muslim, and Buddhist Societies
}

\author{
James H. Liu ${ }^{a}$, Robert Jiqi Zhang ${ }^{a}$, Huajian Cai ${ }^{b}$, Silvia Maric, Xiaoyan Qu ${ }^{d}$, and Ahmet Suerdam ${ }^{e}$
}

${ }^{\mathrm{a}}$ Massey University, Palmerston North, New Zealand; ${ }^{\mathrm{b} C h i n e s e ~ A c a d e m y ~ o f ~ S c i e n c e s, ~ B e i j i n g, ~ C h i n a ; ~}{ }^{\mathrm{c}}$ University of Milan -

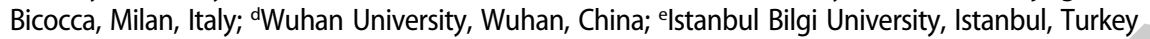

\begin{abstract}
Cosmopolitan Orientation's (COS) relationship with personal religiosity, organizational religiosity, and national identity was examined in nationally representative samples from 19 societies (13 mainly Christian, 2 Muslim, and 4 societies with historically Buddhist influences, $N=8740$ ). Multi-group structural equation models found that personal religiosity was a positive and significant predictor of global prosociality (willingness to help others in a global community) overall ( $b=.18$ ), and in 13 of 19 societies. This relationship was stronger in countries higher on the Human Development Index. National identity was overall a weak and positive predictor of global prosociality $(b=.06)$ and respect for cultural diversity $(b=.07)$, but results were culturally variable. There were negative relationships between national identity and COS indicators in Germany, the UK and USA (countries with active antiimmigration discourses popularized by populist right-wing politicians). Separate analyses for different religious groups found that among Christians, personal religiosity was positively associated with global prosociality, respect for cultural differences, and cultural openness (in that order). Among Buddhists, both personal and organizational religiosity were associated with global prosociality and cultural openness. For the smaller sample of Muslims, the only significant association was the positive link between personal religiosity and global prosociality. Findings support the idea that, contrary to much established literature, there are country-level moderators, but no overall negative relationship between cosmopolitanism and religiosity or national identity at the individual-level across cultures.
\end{abstract}

Historically, the conceptual relationship between religiosity, state sovereignty, and cosmopolitanism has been troubled. Cosmopolitanism, which involves identifying oneself as "a citizen of the world" (Brock, 2013), is often thought of as being "above religion and the state" (Pogge, 1992). It seeks to form a mandate for respecting human rights and taking responsibility for the welfare of others in a global community that transcends religion and state. However, the universality of this mandate is being interrogated on three fronts. One, religion can produce justifications for intergroup conflict ("Holy War") that contest core ideas in cosmopolitanism (Atran \& Ginges, 2012; Preston et al., 2010). Two, states, and nationalists within them, are jealous of their sovereignty, and have mobilized against cosmopolitan (or supra-state) institutions like the European Union (Conversi, 2014). Three, cosmopolitanism assumes different forms in different parts of the world, so a universal form is hard to define (Appiah, 2005) and measure (Roudometof, 2012).

CONTACT James H. Liu J.h.liu@massey.ac.nz @ School of Psychology, Massey University, Private Bag 102904, Auckland 0745, New Zealand.

(1) Supplemental data for this article can be accessed on the publisher's website. 
However, the world continues to rise and fall together economically (Ritzer, 2011, Coronavirus response in 2020 as the most recent example), so there is a need for something that functions conceptually like cosmopolitanism. Both religiosity (Ysseldyk et al., 2010) and nationalism (Mummendey et al., 2001) can be understood as powerfully existing systems of power and identification that may offer resistance to cosmopolitanism (McFarland et al., 2019). But the exact relationship between them is still not well known. Calhoun (2003), for example, wrote "cosmopolitanism need not be presented as the universalistic enemy of particular solidarities" (p. 532), but he did not present empirical evidence for this assertion. So, the question addressed in this research is: what empirical relationship exists between the cosmopolitanism of individuals, and their allegiance to religion and state in different parts of the world?

Conceptually, Connolly (2009) has argued for a reformulation of cosmopolitanism based on a "new pluralism". This requires a switch from trying to achieve a global consensus on ethical and moral universalism above contending faiths, to an ethos of engagement between multiple constituencies. People bring portions of their faiths with them into an interactive public sphere, where cosmopolitanism can connect them. Such formulations are compatible with psychological conceptions of actually existing cosmopolitanism, rather than dealing with philosophical or political ideals that are more purely theoretical. In this way, researchers can see whether individuals might subscribe to aspects of cosmopolitanism, while maintaining loyalty to their culturally dominant sources of values, like religion and nationality (Appiah, 2005; Calhoun, 2003; Connolly, 2009). Leung et al.'s (2015) threefactor construct of Cosmopolitan Orientation, built on theoretical foundations established by the humanities and social sciences, is most suitable for such an endeavor (as Liu et al. (2020) have shown it has metric invariance across 19 countries).

Does cosmopolitanism fly so high above church and state that it bears little relationship with them? Are the aims of cosmopolitanism for an overarching world order hostile to existing aims of church and state? Or, is there a degree of compatibility between cosmopolitanism and adherence to church and state? These questions are addressed empirically, in cross-cultural survey research using large representative samples in 19 countries where three major religions (Christianity, Islam, and Buddhism) are (or were historically) preeminent. These include the formerly Communist state of Russia, and the formally Communist and predominantly non-religious state of China.

\section{A measure of cosmopolitan orientation}

Cosmopolitanism is a concept with lineage, dating back to the ancient Greeks, and revived by enlightenment philosopher Immanuel Kant (Beck, 2002; Cavallar, 2012). It has been conceptualized and operationalized in many ways. The extant empirical literature, dominated by political science and sociology, has relied on survey measures not purpose-built to measure cosmopolitanism at the individual level (see Inglehart \& Baker, 2000; Inglehart \& Welzel, 2005). To fill this gap, Leung et al. (2015) comprehensively reviewed the literature on cosmopolitanism, focusing their attention on theoretical rather than empirical writing, to generate a new, comprehensive, and psychologically compelling measure. ${ }^{1}$ Their review and empirical research identified three factors of cosmopolitanism at the individual level: cultural openness, global prosociality, and respect for cultural diversity (see also Leung \& Koh, 2019).

First, being open and receptive to diverse experiences through interactions with people, places, ideas, and things outside of one's heritage culture is perhaps the defining quality of a cosmopolitan individual (see also Cleveland et al., 2009; Beck, 2002 or Vertovec \& Cohen, 2002 for additional theory). Second, cosmopolitans are theorized to have a sense of global justice, where they recognize local and foreign people as being equally human, and equally worthy of help and human dignity, despite differences in appearance or habits (Brock, 2013; Pogge, 1992). Third, cosmopolitan individuals have "been described as people who identify, respect, and protect cultural differences ... to the

\footnotetext{
${ }^{1}$ See McFarland et al. (2019) for a more comprehensive review of empirical measures of global identification and citizenship.
} 
extent that they afford a "delight in difference" (Leung et al., 2015, p. 80). This factor indexes a willingness to engage with "the other" on an equal or reciprocal basis, respecting differences rather than seeking to overcome them or assimilate them. This conception and three-factor measure of cosmopolitan orientation was validated by Leung et al. (2015) on convenience samples from three countries. It has been further shown to have good psychometric properties worldwide by Liu et al. (2020). The 15-item measure has the desired property of operationalizing cosmopolitanism at the individual-level in a coherent manner without referring to either religiosity or national identity.

\section{Cosmopolitanism and religiosity}

The relationship between cosmopolitanism and religion is regularly theorized as problematic. This is because religion is regarded as a vehicle for parochial altruism: it promotes in-group cooperation, and conflict with out-groups (Preston et al., 2010; Richerson et al., 2016). Summarizing this from an evolutionary perspective, Atran and Ginges (2012) wrote that "sacred values act as moral imperatives that inspire nonrational sacrifices in cooperative endeavors and war generating outsize commitment in low-power groups to resist and often prevail against materially stronger foes" (p. 855). As a specific example of how this might interfere with cosmopolitanism, consider Donnelly's (2007) discussion of Islam's treatment of apostasy: Muslims are forbidden by religious law from renouncing their religion. This could be considered by some as a violation of the universal human right to religious freedom, an important tenet of cosmopolitan theory. When this religious practice is placed in a context where it is competing with another proselytizing religion like Christianity, it is a recipe for sacred conflict.

\section{Different aspects of religiosity}

However, there are aspects of religiosity that may be compatible with cosmopolitanism. The psychology of religion has advanced by distinguishing different aspects of religiosity and examining their functions. For example, a review by Preston et al. (2010) suggests that more socially organized aspects of religion can be connected to ingroup altruism (or outgroup prejudice), whereas more supernatural (or intrinsic) aspects of religion are more linked to universal prosociality.

Empirical research detailing the complex linkages between religiosity and global citizenship has been emerging, but with inconsistent results. In a series of studies based on natives and immigrants in Belgium, Saroglou and colleagues found that some of the (perhaps more intrinsic) aspects of religiosity were positively associated with identification as a world citizen (Saroglou \& Galand, 2004; Saroglou \& Hanique, 2006; Saroglou \& Mathijsen, 2007). However, Katzarska-Miller et al. (2014) and McFarland (2017), examining samples in the United States, found that religiosity had weak or non-significant correlations with identification as a global citizen (although intrinsic and quest religious motivations positively predicted global awareness). Roof (1976), by contrast, predicted and found that localism (or anti-cosmopolitanism) predicted higher religiosity in terms of both church attendance and religious beliefs among a Southern Protestant sample; this suggests a negative relationship between cosmopolitanism and religiosity.

All these results are based on single-country and non-representative samples, which limit generalizability. We extend this literature by testing the individual-level relationship between cosmopolitanism and two aspects of religiosity in representative samples from 19 countries. The measures used in cover two important and separate aspects of religiosity: personal religiosity (i.e., the importance of religion in the individual's personal life) and organizational religiosity (i.e., the importance of religion in state governance). Saroglou (2011) proposed four basic dimensions that characterize religion and religiosity across cultures: believing, bonding, behaving, and belonging. Personal religiosity and organizational religiosity are similar on the dimension of believing, as both acknowledge the importance of transcending surface observations of reality through religion. However, personal religiosity is different from organizational religiosity on three other dimensions: (1) it seeks connection with transcendent entities mainly through personalized practice and experiences (e.g., prayer and meditation) rather than through organized rituals (e.g., going to church or on Hajj); (2) it emphasizes 
internalized moral rules through the cultivation of virtues; and therefore (3) its group component is less prominent. Considering these differences, it is expected that personal religiosity should be positively associated with cosmopolitanism, but organizational religiosity should be negatively associated, or unrelated to cosmopolitanism.

\section{Religion and prosociality}

There is also a substantial literature on religion and prosociality. This literature only indirectly addresses issues of cosmopolitanism. Norenzayan and Shariff (2008), in summarizing the literature, suggest that religion's effect on prosociality depends on (1) the deity(-es) of the religion being morally concerned agents (rather than purely dispassionate observers) where 2) participation in religion under the vigilance of the deity increases reputational concerns of believers to behave pro-socially and reduces their anonymity to one another, and 3) religious devotion to morally vigilant deities activates thoughts of these deities to habitually facilitate prosocial behavior. This literature has shown that religion improves prosociality in situations where thoughts of the religion and its supernatural moral agent(s) are active and salient among believers. According to Smith (2003), this effect is most prevalent in big religious groups, like Christianity or Islam: the bigger the group, the more likely they are to have morally concerned deities that activate/encourage prosocial behavior. We therefore expect positive associations between religiosity, especially personal religiosity, and global prosociality, to a greater extent than the other two factors of cosmopolitan orientation. For cultural openness and respect for cultural diversity, we expect more parochial effects of religiosity, especially organizational religiosity.

\section{Religiosity across cultures}

Classic analysis of the World Values Survey (WVS) constructs religiosity as opposing secular-rational values typical of modernity. Inglehart and Baker (2000) found that traditional values (including belief in the importance of God) were stronger in agrarian societies. They conceptualized these as opposing secular-rational values prevalent in industrialized societies. However, despite this overall trend, they also noted a persistence of values, where countries with Catholic, Protestant, and ex-Communist histories tended to cluster together despite differences in GDP and region. Over time, $60 \%$ of the societies measured (including more advanced and wealthier societies) became more secular-rational in their values from 1981 to 1998 . However, among the other 40\%, ex-Communist states became more religious from 1981 to 1998 (because the collapse of Communism in the 1990s freed people to practice religion). Similarly, Yeşilada and Noordijk (2010) found that Turkish WVS data from the 1990s to 2000s followed this pattern also, where religiosity and other traditional values increased with GDP and other indictors of modernization. ${ }^{2}$

Drawing from this literature, we explore how the link between religiosity and cosmopolitanism may be contingent on country-level predictors and religious affiliations. First, religion as the dominant force for organizing society is on the wane (Inglehart \& Baker, 2000). In this same context, however, religiosity as a personalized form of self-expression has been on the rise in those countries emphasizing self-expressive values (Inglehart \& Welzel, 2005). Therefore, it is expected that the positive link between personal religiosity and cosmopolitanism is stronger in economically advanced and politically democratic (i.e. self expressive) societies. Secondly, the link between religiosity and cosmopolitanism may be contingent on religious affiliation. This hypothesis draws from indirect evidence on religious prejudice, where religiosity and extrinsic religious motivation has a robust association with outgroup prejudice among people affiliated with monotheistic religions (see meta-analysis in Hall et al., 2010; also Hunsberger, 1996); but a reversed pattern was found in East Asian religions, including among Buddhists and Taoists (Clobert et al., 2015, 2014). Therefore, it is expected that religiosity should have a stronger association with cosmopolitanism among people affiliated with non-monotheistic religions (i.e. in our study, Buddhists).

${ }^{2}$ The Republic of Turkey was founded on tenets of secular nationalism as the "correct formula" for modernization, that in recent decades has been over-turned in favor of religious nationalism. 


\section{Cosmopolitanism and nationalism}

States can be described as "imagined communities" (Anderson, 1991) designed to obscure differences between citizens, enhance the ability of government to control individuals, and therefore increase prosociality within the state. But this also puts it into competition with rival states (Smith, 2003). States, like religions, have the ability to increase cooperativeness among ingroup members, but this may also increase competition or conflict with outgroups (Romano et al., 2017). To address this problem, Kant's original conception of cosmopolitanism included a political project to form a federation of states committed to world peace (Cavallar, 2012), like the United Nations. Other resonances of this idea are retained in modern times with the idea that democracies have a duty to band together to fight tyranny (most famously in World War II, see Liu \& Sibley, 2009).

There is a reasonably large literature investigating the relationship between national identity and cosmopolitanism. While most authors agree that cosmopolitanism has multiple dimensions (Vertovec \& Cohen, 2002), there does not appear to be any consensus for operationalizing these (Roudometof, 2012). This is because authors typically rely on data from large scale social surveys where the questions are not purpose-built to examine cosmopolitanism. They ask questions relevant to cosmopolitanism as part of a larger agenda for surveying many aspects of societies. In this literature, there is a consistent emphasis on defining cosmopolitanism as one end of a dimension anchored at the opposite end by national or local identifications. For example, Norris and Inglehart (2009) operationalized cosmopolitanism as a weaker sense of national identification; Olofsson and Öhman (2007) as a weaker sense of attachment to local collectives (hometown, region, and country); Pichler (2011) as a complex 2dimensional composite of numerous variables (including weak support for nationalism). Studies where cosmopolitanism is so defined cannot provide an empirical answer to the question of what is the relationship between cosmopolitanism and national identity. It is a priori operationalized as negative.

In an exception to this trend, Pichler (2008) found that less than half the participants in the Eurobarometer 64.2 survey had some sense of cosmopolitanism (operationalized by different questions, such as identification with Europe or as a citizen of the world). After combining different aspects of attachment using latent class analysis, Pichler (2008) found that cosmopolitanism in the EU was not associated with national pride, but was associated with greater pride in Europe, with greater support for European integration, and lower fears regarding the EU (including fears about loss of national identity). This study suggests that the relationship between cosmopolitanism and national identity does not have to be negative. Further research by psychologists McFarland et al. (2012) using a purpose-built measure of Identification with All Humanity (IWAH) showed that IWAH in the USA was negatively associated with blind patriotism, but had little correlation with constructive patriotism (see McFarland et al., 2019, p. 152).

A thematic analysis summarizing findings from 22 empirical studies of Australian identity since 1998 also raises pertinent issues about the presumed negative relationship between national identity and cosmopolitanism. Austin and Fozdar (2018) note that when cosmopolitanism is rhetorically positioned as a complement to, or expansion of, national identity, it receives considerable support: two thirds of participants agreed and only $11 \%$ disagreed with the statement 'I regard myself as a citizen of the world as well as an Australian citizen". By contrast, when cosmopolitanism is posed as an alternative to or in opposition to national identity, Australians overwhelmingly report greater allegiance to national identity. Therefore, the wording of questions relating cosmopolitanism to national identity may strongly influence resulting data about the degree to which the two are associated.

\section{Summary}

The empirical question of what is the relationship between religion/religiosity, national identification, and cosmopolitanism has not been settled. We examine the empirical relationship between these three concepts in 19 societies around the world. 


\section{Method}

\section{Participants}

The present study analyzed data from the Digital Influence project, a two-wave international online survey, administered by American polling firm Nielsen. Wave 1 was administered in September 2015, and Wave 2 in March 2016. Only respondents who participated in both waves were selected. This resulted in 8740 respondents from 19 countries (or "societies"). Attitudinal measures were collected in Wave 2, whereas demographics were collected in Wave 1; for details about the Wave 1 representative sample, stratified for age, gender, and region, see Gil de Zúñiga \& Liu, 2017). The 19 were: Argentina, Brazil, China, Estonia, Germany, Indonesia, Italy, Japan, S. Korea, New Zealand, the Philippines, Poland, Russia, Spain, Taiwan, Turkey, United Kingdom, Ukraine, the United States. A previous investigation used these data to describe the basic properties of cosmopolitanism, but did not examine its relationship to religion or national identity (Liu et al., 2020).

\section{Measures}

Religious affiliation was measured in Wave 1 by an open-ended question "What is your religion?". The answers were coded into (1) Christian, (2) Muslim, (3) Buddhist, (4) other religions, (5) Atheist/ Agnostic, (6) not religious, and (7) unreported.

Religiosity was measured in Wave 2 by two single-item measures: (1) Personal religiosity: "How important is religion to your life?" (answered on a four-point Likert scale ranging from $1=$ "not important" to 4 = "extremely important"); (2) Organizational religiosity: "What part do you think religion should play in governance?" (answered on a four-point Likert scale ranging from 1 = "no part at all" to 4 = "an extremely important part").

National identity was measured in Wave 2 with four items drawn from different studies assessing different facets of national identification: (1) "Being [nationality] is very important to $m e$ " (Citrin et al., 1990); (2) "To what extent do you see yourself as a typical [nationality]" (Huddy \& Khatib, 2007); (3) "The term [nationality] describes me well"; (4) "I identify with my nationality" (Postmes et al., 2012). ${ }^{3}$ Responses to these items were recorded on a seven-point Likert scale ranging from $1=$ "completely disagree" to $7=$ "completely agree". The scale was highly reliable (Cronbach's $\alpha=.93$ ).

Cosmopolitan Orientation (COS) was measured in Wave 2 by a 15 -item scale developed by Leung et al. (2015). COS consisted of three factors: global prosociality (e.g., "I would serve the world community by helping human beings"; "When people from other countries are in need, I will help them to the best of my abilities"), cultural openness (e.g., "I am open to living in a different culture"; "I am willing to study or work abroad in another culture"), and cultural diversity (e.g., "It is important to preserve the authenticity of native cultures"; "I respect cultural differences"). Responses to these items were recorded on a seven-point Likert scale ranging from 1 = "disagree completely" to 7 = "agree completely". The scale was highly reliable (Cronbach's $\alpha=.92$ for global prosociality, .90 for cultural openness, .86 for respect for cultural diversity).

Human Development Index (HDI; UNDP, 2015) was used as a country-level indicator of overall development. It encompasses education, lifespan, and per capita GDP as indicators of development.

Demographics were measured in Wave 1, including age, gender, and self-reported social status ("On a scale of 1 to 10 , with 10 being the people who are the most well off, and 1 being the people who are the least well off, where would you describe your position?").

${ }^{3}$ Note that the same pattern of findings reported herein was found using the four items, only the three items adapted from Huddy and Khatib (2007), and only the single-item social identification measure (Postmes, Haslam, \& Jans, 2012), so the finding are robust. 
Multigroup structural equation modeling (MGSEM) was used to test the associations between religiosity, national identity, and COS across cultures. To test whether the structural model (i.e., regression parameters) was invariant across societies, two MGSEM models were estimated and compared for each analysis. ${ }^{4}$ An overall model was estimated first, where all regression parameters in the structural model were constrained to be equal. Then a group-specific model was estimated (country and religious affiliation were used as the grouping variable in different analyses), where all regression parameters in the structural model were freely estimated. In all these models, factor loadings were constrained to be equal across groups (i.e., metric invariance), and after examining modification indices to improve fit, the residuals of COS items 14 and 15 were allowed to correlate in Estonia. A set of criteria were used to assess model fit, including Chi-square value, Root Mean Square Error of Approximation (RMSEA), Comparative Fit Index (CFI), Tucker-Lewis Index (TLI), and Standardized Root Mean Square Residual (SRMR). RMSEA $\leq .08$, CFI $\geq .90$, TLI $\geq .90$, and SRMR $\leq .10$ were considered acceptable model fit (Vandenberg \& Lance, 2000). Finally, we compared these two models by using the Chi-square difference test. Given the large sample size, a significance level of $p<.001$ was chosen for tests involving the entire sample of 8740 individuals. A conventional $p<.05$ was selected for country-specific tests involving smaller samples.

Multilevel regressions were then used to scrutinize potential cross-national variations. Three COS factors were included as dependent variables in separate models. Firstly, individual-level models (Model 1) were estimated, using a random intercept and fixed-effect individual-level predicters (i.e., personal religiosity, organizational religiosity, and national identity). Then, cross-level interaction models (Model 2) were estimated by including random individual-level predictors, a country-level predictor (i.e., Human Development Index), and cross-level interactions. Both multigroup and multilevel analyses were conducted in MPlus 7.31 with an MLR estimator.

\section{Results}

\section{Descriptive analysis}

Correlations and descriptive statistics are presented in Table 1. Demographics, mean levels of religiosity, and mean levels of national identity for every religious affiliation are presented in Supplementary Table 3 . The sample had $46.8 \%$ of respondents self-identifying as Christians, $6.1 \%$ as Muslims, $5.3 \%$ as Buddhists, $4.1 \%$ affiliated with other religions, $5.6 \%$ as Atheists, $26.3 \%$ as not religious; $5.9 \%$ of respondents did not report their religious affiliation.

Analysis of variance (for continuous dependent variables) and a Chi-square test of independence (for categorical dependent variables) compared differences across religious affiliations in terms of demographics and religiosity. There was a significant difference across groups with respect to age, $F(6$, $8658)=25.66, p<.001, \eta^{2}=.017$. Respondents affiliated with Islam were the youngest. The relationship between religious affiliation and gender was significant, $\chi^{2}(6)=54.21, p<.001, \omega=.079$. The highest proportion of females was among Christians, followed by other religions, finally Muslims, the not religious, atheists, and Buddhists. There was a significant difference with respect to self-reported social status, $F(6,8690)=22.90, p<.001, \eta^{2}=.016$. Muslims had the highest self-reported social status, followed by Christians and atheists, Buddhists, other religions, and not religious respondents had the lowest.

Critically, there was a significant difference with respect to personal religiosity, $F(6,8236)=534.60$, $p<.001, \eta^{2}=.280$. Personal religion was given the most importance among Muslims, followed by Christians, other religions, and Buddhists, and the least among not religious respondents and atheists. There was also a significant difference with respect to organizational religiosity (or importance of

${ }^{4}$ Measurement invariance testing suggested that these two scales had metric invariance across 19 countries/societies, and scalar invariance across seven religious affiliations (see Supplementary Tables 1 and 2). 
Table 1. Correlations and descriptive statistics for cosmopolitan orientation, religiosity, and national identity.

\begin{tabular}{|c|c|c|c|c|c|c|}
\hline & 1 & 2 & 3 & 4 & 5 & 6 \\
\hline \multicolumn{7}{|l|}{1 Global Prosociality } \\
\hline 2 Cultural Openness & $.550^{* *}$ & & & & & \\
\hline 3 Respect for Cultural Diversity & $.531^{* *}$ & $.625^{* *}$ & & & & \\
\hline 4 Personal Religiosity & $.183^{* *}$ & $.070^{* *}$ & $.082^{* *}$ & & & \\
\hline 5 Organizational Religiosity & $.130^{* *}$ & $.084^{* *}$ & $.038^{* *}$ & $.526^{* *}$ & & \\
\hline 6 National Identity & $.043^{* *}$ & $-.093^{* *}$ & $.100^{* *}$ & $.197^{* *}$ & $.093^{* *}$ & \\
\hline M & 4.38 & 4.55 & 5.16 & 1.97 & 1.85 & 5.12 \\
\hline$S D$ & 1.29 & 1.38 & 1.10 & 1.02 & 0.96 & 1.47 \\
\hline
\end{tabular}

** Correlation is significant at the.01 level (two-tailed).

religion in governance), $F(6,8242)=146.56, p<.001, \eta^{2}=.096$. Organizational religiosity was most important among Muslims, followed by Christians, Buddhists, and other religions, and the least among atheists and the not religious.

Proportions of different religious affiliations, mean levels of personal religiosity, organizational religiosity, and national identity for every country are presented in Supplementary Table 4. Christianity was the predominant religion in 12 of the countries, including Argentina, Brazil, Germany, Italy, New Zealand, the Philippines, Poland, Russia, Spain, UK, Ukraine, and the US. Estonia and South Korea had a higher proportion of Christian (30.7\% and 34.4\%, respectively) than any other religions, although this was lower than the non-religious (38.9\% and 51.4\%, respectively). Islam was the predominant religion in Indonesia (66.6\%) and Turkey (90.6\%). Japan had a higher proportion of Buddhists (35.0\%) than any other religion, although this was lower than the not religious (53.0\%). Taiwan had a high proportion of other religions $(24.6 \%$, mainly Taoism or a mixture of Taoism and Buddhism) and Buddhists (24.2\%), as well as 37.1\% non-religious. China and South Korea also had significant but small proportions of respondents affiliating with Buddhism (12.7\% and $12.6 \%$, respectively). China had the largest proportion of not religious respondents $(73.9 \%)$.

\section{Religiosity, national identity, and cosmopolitan orientation across societies}

The overall MGSEM model showed an acceptable model fit: $\chi^{2}(3775)=11515.484$, RMSEA $=.067$ $[.066, .069]$, CFI $=.909$, TLI $=.904$, SRMR $=.100$ (see Figure I and Supplementary Table 5). This universal model results suggested a single significant and positive association between COS and religiosity across cultures: personal religiosity was positively associated with global prosociality $(b=.18$, s.e. $=.02, p<.001)$.

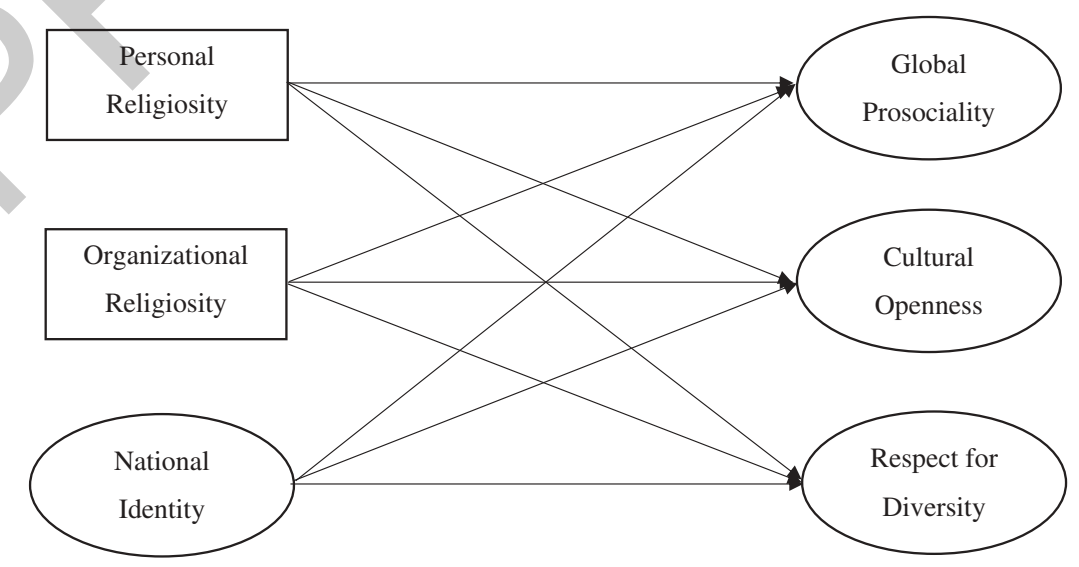

Figure I. Multi-group structural equation model of religiosity, national identity, and 3 factors of cosmopolitan orientation. 
Beyond this signal finding, national identity also had consistent positive associations with COS: it was positively associated with global prosociality $(b=.06$, s.e. $=.01, p<.001)$ and, also surprisingly, respect for cultural diversity $(b=.07$, s.e. $=.01, p<.001)$.

The country-specific model also showed an acceptable model fit: $\chi^{2}(3613)=11004.317$, RMSEA $=.067[.066, .069]$, CFI $=.913$, TLI $=.905$, SRMR $=.077$ (see results in Figure IIA-C and more detailed results in Supplementary Table 6). Importantly, this country-specific model had a significantly better model fit than the overall universal model (Sattora-Bentler Scaled $\Delta \chi^{2}$ $(162)=514.202, p<.001)$. This demonstrates that the universal model did not fit the data as well as allowing for cross-national variations among the regression parameters.

Personal religiosity had a significantly positive association with global prosociality in 13 out of 19 societies, and all non-significant associations were positive except in Ukraine. Personal religiosity also had a significantly positive association with cultural openness in 3 societies (i.e., South Korea, Russia, and Spain), and a significantly positive association with respect for cultural diversity in 4 societies (i.e., Poland, Russia, Spain, and UK). However, these latter two links were quite variable, with both positive and negative non-significant associations across cultures. Only the positive link between personal religiosity and global prosociality was relatively universal across our sample of societies.

Organizational religiosity had a variable relationship with COS. Despite the overall non-significance levels reported previously, it had a significantly positive association with global prosociality in 2 societies (i.e., China and Japan). It had a significantly positive association with cultural openness in 2 societies (i.e., China and Ukraine), together with a significantly negative association in 3 other countries (i.e., Russia, Spain and the US). It had a significantly negative association with respect for cultural diversity in 4 societies (i.e., Argentina, Poland, Spain, and the US), but a significantly positive association in China. Therefore, there was no universal link between organizational religiosity and COS.
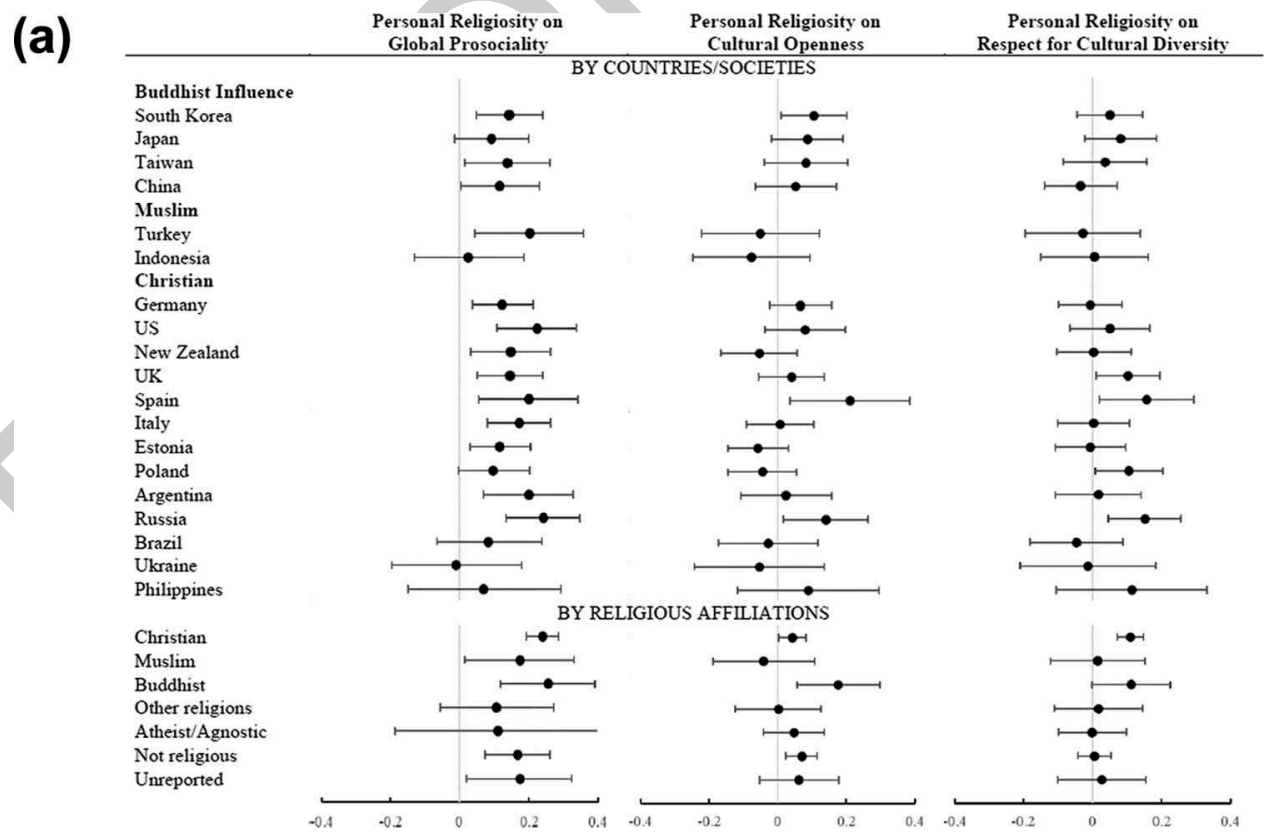

Figure IIA. Forest plot showing effects of personal religiosity on cosmopolitan orientation (standardized regression coefficients and the $95 \%$ confidence interval) for each country/society (on the upper part of the figure) and religious affiliation (on the lower part). Countries/societies are first categorized based on the dominant religions, and then sorted descendingly by HDI within the same religion. 


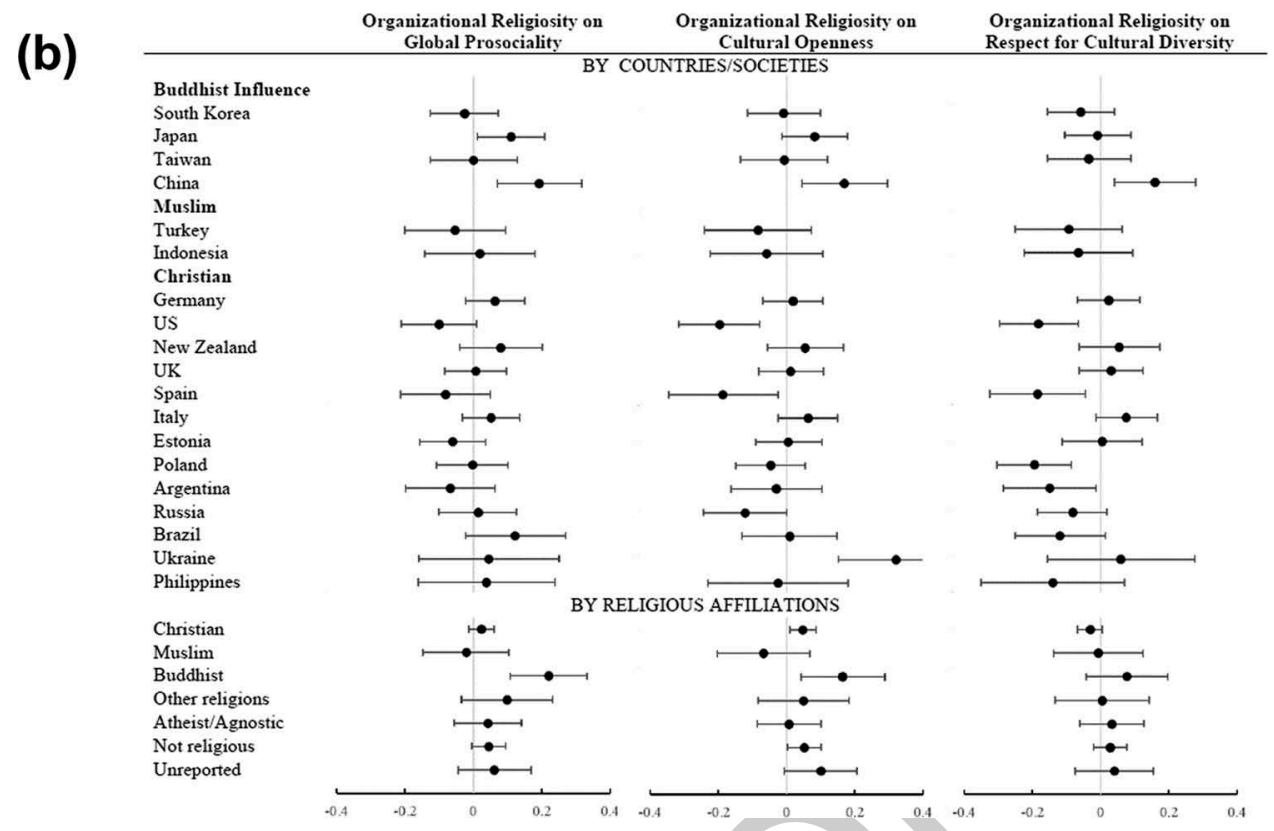

Figure IIB. Forest plot showing effects of organizational religiosity on cosmopolitan orientation (standardized regression coefficients and the $95 \%$ confidence interval) for each country/society (on the upper part of the figure) and religious affiliation (on the lower part). Countries/societies are first categorized based on the dominant religions, and then sorted by HDI descending within the same religion.

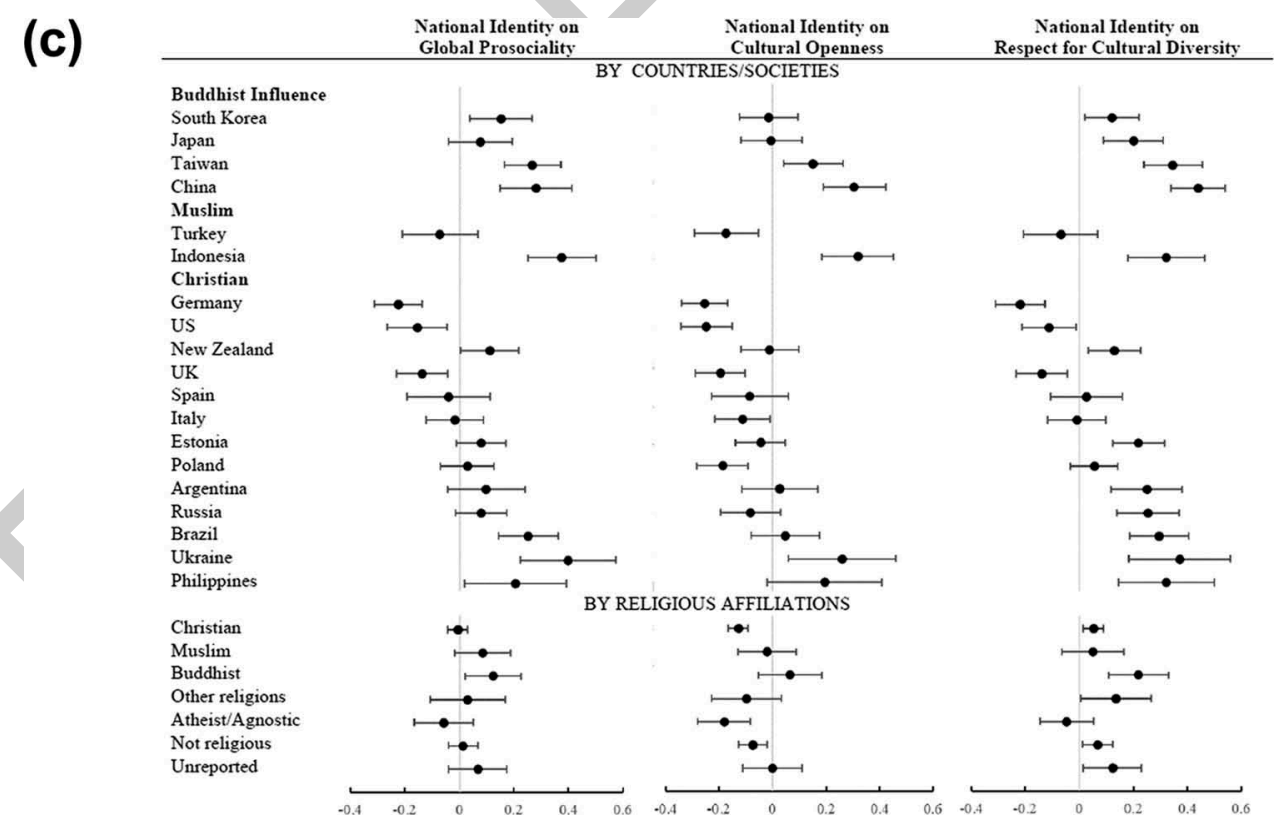

Figure IIC. Forest plot showing effects of national identity on cosmopolitan orientation (standardized regression coefficients and the $95 \%$ confidence interval) for each country/society (on the upper part of the figure) and religious affiliation (on the lower part). Countries/societies are first categorized based on the dominant religions, and then sorted by HDI descending within the same religion. 
National identity had a complex and cross-nationally variable association with COS. National identity had a significantly positive association with global prosociality in 8 out of 19 societies, but a significantly negative association in 3 societies (i.e., Germany, the UK, and the US). It also had a significantly positive association with respect for cultural diversity in 12 out of 19 societies, but a significantly negative relationship in 3 other societies (again Germany, the UK, and the US). National identity had a significantly negative association with cultural openness in 6 societies (i.e., Germany, Italy, Poland, Turkey, the UK, the US), but a significantly positive association in 4 societies (i.e., China, Indonesia, Taiwan, and Ukraine).

Overall, national identity was positively associated with global prosociality and respect for cultural diversity in most societies. Surprisingly, the consistent exceptions for this positive link were Germany, the UK, and the US, among the most economically advanced societies in the world.

The association between national identity and cultural openness varied across societies. Indonesia and Turkey, which were the two predominantly Muslim societies in our sample, had strikingly different outcomes: Indonesians had a moderately positive relationship between national identity and COS, whereas Turks had a weak negative relationship between the two. This may well reflect greater religious fundamentalism in Turkey.

Multilevel regressions were used to further examine country-level moderation of these results by HDI. Results suggested that global prosociality was positively associated with personal religiosity. This link was moderated by the HDI, in that the association was more positive in countries with higher HDI (in accord with expectations). By contrast, organizational religiosity was not significantly associated with any factor of COS. National identity had more variable associations with COS: it was positively associated with respect for cultural diversity, but negatively associated with cultural openness. All these links (including its non-significant association with global prosociality) were moderated by HDI, in that associations were more negative (or less positive) in countries with higher HDI (see Supplementary Table 7).

\section{Religiosity, national identity, and cosmopolitan orientation across major religious affiliations}

The overall model showed an acceptable model fit: $\chi^{2}(1376)=7284.770$, RMSEA $=.059[.058, .060]$, $\mathrm{CFI}=.925, \mathrm{TLI}=.920, \mathrm{SRMR}=.059$ (see results in Supplementary Table 8). The religion-specific model also showed an acceptable model fit: $\chi^{2}(1322)=7129.365$, RMSEA $=.060[.058, .061]$, $\mathrm{CFI}=.926, \mathrm{TLI}=.918, \mathrm{SRMR}=.054$ (see results in Figure IIA-C), and this model had a significantly better model fit than the overall model (Sattora-Bentler Scaled $\Delta \chi^{2}(54)=125.137, p<.001$ ). Here we focus on the links between religiosity, national identity, and COS among three major religions. ${ }^{5}$ More detailed results (including results for other religious affiliations) can be seen in Supplementary Table 9.

Among Christians, personal religiosity was positively associated with global prosociality $(\beta=.20$, s. e. $=.02, p<.001)$, respect for cultural diversity $(\beta=.11$, s.e. $=.02, p<.001)$, and cultural openness $(\beta=.04$, s.e. $=.02, p=.027)$. Organizational religiosity was positively associated with cultural openness $(\beta=.05$, s.e. $=.02, p=.014)$. National identity was negatively associated with cultural openness $(\beta=-.13$, s.e. $=.02, p<.001)$, but positively associated with respect for cultural diversity $(\beta=.05$, s. e. $=.02, p=.006)$.

Among Muslims, the only significant association was the positive link between personal religiosity and global prosociality $(\beta=.15$, s.e. $=.07, p=.028)$.

Among Buddhists, personality religiosity was positively associated with global prosociality $(\beta=.20$, s.e. $=.05, p<.001)$ and cultural openness $(\beta=.18$, s.e. $=.06, p=.004)$. Organizational religiosity was positively associated with global prosociality $(\beta=.22$, s.e. $=.06, p<.001)$ and cultural openness $(\beta=.17$, s.e. $=.06, p=.009)$. National identity was positively associated with global prosociality $(\beta=.12$, s.e. $=.05, p=.017)$ and respect for cultural diversity $(\beta=.22$, s.e. $=.06, p<.001)$.

${ }^{5}$ Because these involve three separate regression analyses, we report standardized beta coefficients to allow comparison between the three religious groups. 
Overall, personal religiosity was associated with global prosociality consistently across three major religions. However, the impacts of organizational religiosity and national identity on cosmopolitan orientation were more variable. These links were consistently positive among Buddhists, but at times negative among Christians, and non-significant among Muslims.

\section{Discussion}

A global examination of the individual-level relationship between cosmopolitanism, religiosity, and national identity across cultures resulted in a definite answer to an important question. It revealed that there is NO necessarily negative relationship between cosmopolitanism and religiosity, or cosmopolitan and national identification. In fact, the most definitive relationship found was a positive and largely consistent association between cosmopolitan prosociality, measured as a willingness to help others (regardless of nationality) and personal religiosity. A MGSEM found that this overall relationship was significant in 13 countries, and overall $(b=.18)$. There was only one, slightly negative and non-significant association $(b=-.01)$ between global prosociality and personal religiosity in the 19 societies surveyed, and this was in Ukraine (under attack by Russia at the time of the survey).

Other relationships were more culturally variable, and deserve to be discussed in context and with nuance. There was an overall positive relationship between national identity and cosmopolitan prosociality, as well as respect for cultural diversity, but these results were not consistent. One of the most striking findings was that despite the overall positive association globally, three of the most advanced democracies in the world, the US, UK, and Germany, were found to have significantly negative associations between national identity and both global prosociality and respect for cultural diversity. A likely explanation for this result is the recent political backlash against neo-liberal economics in these countries. Anti-immigration and anti-globalization nationalist movements, led by populists like Donald Trump, Boris Johnson, and Alexander Gauland (co-leader of the right-wing Alternative for Germany political party) ${ }^{6}$ were very vocal in these countries.

This result is not simply a result of these three countries' advanced economics, as Japan, S. Korea, and New Zealand, three wealthy societies in the Asia-Pacific all showed the opposite result (positive associations between COS and national identity). It appears that the relationship between national identity and COS can be produced by salient anti-immigration nationalist discourses prevalent in a certain time and place, as opposed to being a "natural relationship" between the two concepts (for details of the situation in Germany, see Schumann et al., 2019; for relevant research on global antiimmigration attitudes, see Araújo et al., 2020).

Reese's (2007) framing theory is a promising avenue for understanding these results. He suggests that mass media (through journalists, see Lewis \& Reese, 2009) reflects dominant discourses purposefully disseminated by political and economic elites to organize and structure (frame) public issues. Bush's "War on Terror" would be one such frame (Lewis \& Reese, 2009). This theory appears to be consistent with a general understanding of the political agendas and ability to shape mass media by President Recep Erdogan in Turkey, and President Joko Widodo in Indonesia. While they both lead formally secular Muslim majority states, Erdogan has promoted religious nationalism (see Yilmaz \& Bashirov, 2018), whereas Widodo has focused on economic development (see Warburton, 2016). These differing political agenda appear to be reflected in the negative associations between cosmopolitanism and national identity in Turkey, compared to positive associations in Indonesia. We do not generalize further about Muslims in our data, since they came mainly from these two quite disparate societies.

On the other hand, an overall summary of results for our robust sample of $4000+$ Christians (across 12 predominantly Christian societies encompassing a huge range of political, social, and economic diversity) is meaningful. The personal religiosity of Christians had significantly positive relationships

${ }^{6} \mathrm{~A}$ non-significant, but negative coefficient was also found in Italy, another advanced Western economy with salient anti-immigration and anti-globalization discourses. 
overall with cosmopolitanism, with the strongest relationship being with global prosociality, the weakest relationship with cultural openness. Respect for diversity was intermediate. It is of comfort to observe that a key message of Christianity, "Being a Good Samaritan" has been confirmed in a global sample of Christians. However, in keeping with previous research showing that there are parochial elements associated with this monotheistic religion, the relationship between cultural openness and personality religiosity was only slightly positive, and its link to national identity was significantly negative among Christians.

Our results are largely in accord with previous research showing that more intrinsic elements of the religious experience are more cosmopolitan (Saroglou \& Galand, 2004), and less parochial than extrinsic or socially organized forms of religiosity (Preston et al., 2010). They add to this literature in underlining globally prosocial, axial age (Jaspers, 1953) elements of religion more strongly than in some previous work (see Atran \& Ginges, 2012). Furthermore, some of the strongest positive cosmopolitan connections with religiosity, both personal and organizational, were found in among Buddhists. This is in accord with work by Clobert et al. (2015), and contests Norenzayan and Shariffs (2008) notion that a morally vigilant deity is responsible for the prosociality of axial age religions. It appears that the impersonal doctrine of Karma (e.g., just consequences for good and bad behavior through a cycle of birth and rebirth) works just as well, if not better.

Other culturally variable results may reflect enduring effects resulting from political geography (Kaplan, 2009). Ukraine and Taiwan were found to have among the strongest positive associations between national identity and both global prosociality and respect for diversity. Perhaps in these cases, a sense of reciprocal altruism (Romano et al., 2017) motivates this association: the future survival and well-being of societies like Ukraine and Taiwan depends on good will and support from the international community, because of their proximity to powerful (and potentially threatening) neighbors. So it makes sense for Taiwanese and Ukrainian nationalists to express good will and acceptance to others who are culturally diverse or different; they could be much-needed allies.

We might also speculate that some other societies with strong positive associations between national identity and COS, like China, Indonesia, and the Philippines, are this way because they have respect for ethnic diversity written into their constitutions (equal rights for minorities is a basic principle of the 1954 Chinese Constitution, the Pancasila of Indonesia recognizes 5 religions as part of its state, and the 1987 Constitution of the Philippines recognizes autonomous regions). While each of these countries may fall short of its constitutional ideals, these ideals may still shape the social construction of the link between national identity and cosmopolitanism (for a representational theory approach to understanding this, see Sibley \& Liu, 2007).

These results are important for both theoretical and practical reasons. Previous research (e.g., Norris \& Inglehart, 2009; Olofsson \& Öhman, 2007; Pichler, 2011) has often conceptualized cosmopolitanism at one end of a uni-dimensional spectrum anchored by religiosity or nationalism (as elements of tradition) at the opposite end. Our research, using the purpose-built measure of COS, shows that there is no necessarily negative relationship between cosmopolitanism and aspects of traditionality like religiosity or national identity. Rather, consistent with the "axial age" formulation of Karl Jaspers (1953), levels of personal religiosity across our mainly Christian, but also Muslim and Buddhist samples from around the world were positively associated with global prosociality, a willingness to help all others, not necessarily just members of one's own group. Jaspers theorized that the idea of transcendent religion arose independently around the world between 800-200 BC, as a more universalized and humanely self-aware religious sense. Such religion is capable of supporting large scale cooperation (Richerson et al., 2016) and was perhaps responsible for transforming human society (for a brief account, see Jaspers, 1948).

That axial age religions could still form the basis for some sense of global consciousness (Liu \& Macdonald, 2016) is good medicine for an era where religious fundamentalism appears to be rising, and a "clash of civilizations" has been theorized. Against this idea of a "clash of civilizations", individuals' support for religious governance in our study was unrelated to cosmopolitanism except in a few societies (e.g., Poland, where there is a rising sense of religious fundamentalism coinciding 
with anti-immigration rhetoric, see Wiktor et al., under review; or the USA, where some religious denominations have become overtly political, see Wilcox, 2018). Furthermore, among Buddhists, organizational religiosity was positively associated with global prosociality and cultural openness, and there were no significant associations of organizational religiosity with cosmopolitanism.

The current study has limitations that require future scrutiny. The cross-sectional nature of the current study does not allow for claims about causality, nor does the measure of cosmopolitanism used here capture concrete behaviors. Longitudinal or experimental designs using behavioral measures as dependent variables are encouraged to further validate the conclusions. Moreover, the effect sizes in this study are small in general ( $r<.3$, Cohen, 1988), which needs to be interpreted with caution.

The overall message of this research is still clear: it appears that there is no necessarily negative relationship between cosmopolitanism and religiosity or national identity as individual-level constructs. Rather, there appears to be an "axial age" positive relationship between personal religiosity and global prosociality that is common across cultures. Other relationships between COS, religiosity, and national identity appear to be socially constructed (i.e. moderated) by the history, politics, and belief systems of different cultures, religions, regions, or states. The take home message of this research is that both individuals and societies can take action to construct a more globally just "cosmopolitan society", and it is possible for this to flow through the established institutions of church and state.

\section{Disclosure statement}

No potential conflict of interest was reported by the authors.

\section{Funding}

This research was supported by Grant FA2386-15-1-0003 from the Asian Office of Aerospace Research and Development.

\section{References}

Anderson, B. R. (1991). Imagined communities: Reflections on the origin and spread of nationalism. Verso.

Araújo, R. C. R., Bobowik, M., Vilar, R., Liu, J. H., Gil de Zuñiga, H., Kus, L., Lebedeva, N., \& Gouveia, V. V. (2020). Human values and ideological beliefs as predictors of attitudes towards immigrants across 20 countries: The countrylevel moderating role of threat. European Journal of Social Psychology, 50(3), 534-546. https://doi.org/10.1002/ejsp. 2635

Atran, S., \& Ginges, J. (2012). Religious and sacred imperatives in human conflict. Science, 336(6083), 855-857. https:// doi.org/10.1126/science.1216902

Austin, C., \& Fozdar, F. (2018). Australian national identity: Empirical research since 1998. National Identities, 20(3), 277-298. https://doi.org/10.1080/14608944.2016.1244520

Beck, U. (2002). The cosmopolitan society and its enemies. Theory, Culture \& Society, 19(1-2), 17-44. https://doi.org/10. $1177 / 026327640201900101$

Bielefeldt, H. (1995). Muslim voices in the human rights debate. Human Rights Quarterly, 17(4), 587-617. https://doi. org/10.1353/hrq.1995.0034

Brock, G. (2013). Contemporary cosmopolitanism: Some issues. Philosophy Compass, 8(8), 689-698. https://doi.org/10. $1111 /$ phc3.12054

Calhoun, C. (2003). 'Belonging' in the cosmopolitan imaginary. Ethnicities, 3(4), 531-553. https://doi.org/10.1177/ 1468796803003004005

Cavallar, G. (2012). Cosmopolitanisms in Kant's philosophy. Ethics \& Global Politics, 5(2), 95-118. https://doi.org/10. 3402/egp.v5i2.14924

Cleveland, M., Laroche, M., \& Papadopoulos, N. (2009). Cosmopolitanism, consumer ethnocentrism, and materialism: An eight-country study of antecedents and outcomes. Journal of International Marketing, 17(1), 116-146. https://doi. org/10.1509/jimk.17.1.116

Clobert, M., Saroglou, V., \& Hwang, K. K. (2015). Buddhist concepts as implicitly reducing prejudice and increasing prosociality. Personality and Social Psychology Bulletin, 41(4), 513-525. https://doi.org/10.1177/0146167215571094 
Clobert, M., Saroglou, V., Hwang, K. K., \& Soong, W. L. (2014). East Asian religious tolerance-A myth or a reality? Empirical investigations of religious prejudice in East Asian societies. Journal of Cross-Cultural Psychology, 45(10), 1515-1533. https://doi.org/10.1177/0022022114546641

Cohen, J. (1988). Statistical power analysis for the behavioral sciences (2nd ed.). Lawrence Erlbaum Associates.

Connolly, W. E. (2009). Speed, concentric cultures and cosmopolitanism. In H. Rosa \& W. E. Scheuerman (Eds.), Highspeed society: Social acceleration, power and modernity (pp. 261-286). Penn State University Press.

Conversi, D. (2014). Between the hammer of globalization and the anvil of nationalism: Is Europe's complex diversity under threat? Ethnicities, 14(1), 25-49. https://doi.org/10.1177/1468796813487727

Donnelly, J. (2007). The relative universality of human rights. Human Rights Quarterly, 29(2), 281-306. https://doi.org/ 10.1353/hrq.2007.0016

Gil de Zúñiga, H., \& Liu, J. H. (2017). Second screening politics in the social media sphere: Advancing research on dual screen use in political communication with evidence from 20 countries. Journal of Broadcasting \& Electronic Media, 61(2), 193-219. https://doi.org/10.1080/08838151.2017.1309420

Hall, D. L., Matz, D. C., \& Wood, W. (2010). Why don't we practice what we preach? A meta-analytic review of religious racism. Personality and Social Psychology Review, 14(1), 126-139. https://doi.org/10.1177/1088868309352179

Hunsberger, B. (1996). Religious fundamentalism, right-wing authoritarianism, and hostility toward homosexuals in non-Christian religious groups. The International Journal for the Psychology of Religion, 6(1), 39-49. https;//doi.org/ 10.1207/s15327582ijpr0601_5

Ibrahim, M. (1990). Merchant capital and Islam. University of Texas Press.

Inglehart, R., \& Baker, W. E. (2000). Modernization, cultural change, and the persistence of traditional values. American Sociological Review, 65(1), 19-49. https://doi.org/10.2307/2657288

Inglehart, R., \& Welzel, C. (2005). Modernization, cultural change, and democracy: The human development sequence. Cambridge University Press.

Jaspers, K. (1948). The axial age of human history. Commentary, 6, Periodicals Archive Online 430-435.

Jaspers, K. (1953). The origin and goal of history. Routledge \& Kegan Paul.

Kaplan, R. (2009). The revenge of geography. Foreign Affairs, 172, 96-105.

Katzarska-Miller, I., Barnsley, C. A., \& Reysen, S. (2014). Global citizenship identification and religiosity. Archive for the Psychology of Religion, 36(3), 344-367. https://doi.org/10.1163/15736121-12341291

Khan, S. S., Garnett, N., Hult Khazaie, D., Liu, J. H., \& Gil de Zúñiga, H. (2019). Opium of the people? National identification predicts well-being over time. British Journal of Psychology. https://doi.org/10.1111/bjop.12398

Leung, A., \& Koh, B. (2019). Understanding pro-environmental intentions by integrating insights from social mobility, cosmopolitanism, and social dominance. Asian Journal of Social Psychology, 22(2), 213-222. https://doi.org/10.1111/ ajsp. 12348

Leung, A., Koh, K., \& Tam, K. (2015). Being environmentally responsible: Cosmopolitan orientation predicts proenvironmental behaviors. Journal of Environmental Psychology, 43, 79-94. https://doi.org/10.1016/j.jenvp.2015.05.011

Lewis, S. C., \& Reese, S. D. (2009). What is the war on terror? Framing through the eyes of journalists. Journalism \& Mass Communication Quarterly, 86(1), 85-102. https://doi.org/10.1177/107769900908600106

Liu, J. H., \& Macdonald, M. (2016). Towards a psychology of global consciousness. Journal for the Theory of Social Behavior, 46(3), 310-334. https://doi.org/10.1111/jtsb.12101

Liu, J. H., \& Sibley, C. G. (2009). Culture, social representations, and peacemaking: A symbolic theory of history and identity. In C. Montiel \& N. Noor (Eds.), Peace psychology in Asia (pp. 21-42). Springer.

Liu, J. H., Zhang, R. J., Leung, A., Gil de Zúñiga, H., Gastardo-Conaco, C., Vasiutynskyi, V., \& Kus-Harbord, L. (2020). Empirical correlates of cosmopolitan orientation: Etiology and functions in a worldwide representative sample. Political Psychology, 41(4), 661-678. https://doi.org/10.1111/pops.12644

McFarland, S. (2017). Identification with all humanity: The antithesis of prejudice, and more. In S. G. Sibley \& F. K. Barlow (Eds.), Cambridge handbook on the psychology of prejudice (pp. 632-654). Cambridge University Press.

McFarland, S., Hackett, J., Hamer, K., Katzarska-Miller, I., Malsch, A., Reese, G., \& Reysen, S. (2019). Global human identification and citizenship: A review of psychological studies. Advances in Political Psychology, 40(S1), 141-170. https://doi.org/10.1111/pops.12572

McFarland, S., Webb, M., \& Brown, D. (2012). All humanity is my ingroup: A measure and studies of identification with all humanity. Journal of Personality and Social Psychology, 103(5), 830-853. https://doi.org/10.1037/a0028724

Mummendey, A., Klink, A., \& Brown, R. (2001). Nationalism and patriotism: National identification and out-group rejection. British Journal of Social Psychology, 40(1), 159-172. https://doi.org/10.1348/014466601164740

Norenzayan, A., \& Shariff, A. F. (2008). The origin and evolution of religious prosociality. Science, 322(5898), 58-62. https://doi.org/10.1126/science.1158757

Norris, P., \& Inglehart, R. (2009). Cosmopolitan communications: Cultural diversity in a globalized world. Cambridge University Press.

Olofsson, A., \& Öhman, S. (2007). Cosmopolitans and locals: An empirical investigation of transnationalism. Current Sociology, 55(6), 877-895. https://doi.org/10.1177/0011392107081991

Pichler, F. (2008). How real is cosmopolitanism in Europe? Sociology, 42(6), 1107-1126. https://doi.org/10.1177/ 0038038508096936 
Pichler, F. (2011). Cosmopolitanism in a global perspective: An international comparison of open-minded orientations and identity in relation to globalization. International Sociology, 27(1), 21-50. https://doi.org/10.1177/ 0268580911422980

Pogge, T. W. (1992). Cosmopolitanism and sovereignty. Ethics, 103(1), 48-75. https://doi.org/10.1086/293470

Preston, J., Ritter, R. S., \& Hernandez, J. I. (2010). Principles of religious prosociality: A review and reformulation. Social and Personality Psychology Compass, 4(8), 574-590. https://doi.org/10.1111/j.1751-9004.2010.00286.x

Price, D. (2002). Islam and human rights: A case of deceptive first appearances. Journal for the Scientific Study of Religion, 41(2), 213-225. https://doi.org/10.1111/1468-5906.00112

Reese, S. D. (2007). The framing project: A bridging model for media research revisited. Journal of Communication, 57 (1), 148-154. https://doi.org/10.1111/j.1460-2466.2006.00334.x

Richerson, P., Baldini, R., Bell, A. V., Demps, K., Frost, K., Hillis, V., Mathew, S., Newton, E. K., Naar, N., Newson, L., Ross, C., Smaldino, P. E., Waring, T. M., \& Zefferman, M. (2016). Cultural group selection plays an essential role in explaining human cooperation: A sketch of the evidence. Behavioral and Brain Sciences, 39, e30. https://doi.org/10. 1017/S0140525X1400106X

Ritzer, G. (2011). Globalization: The essentials. John Wiley \& Sons.

Romano, A., Balliet, D., Yamagishi, T., \& Liu, J. H. (2017). Parochial trust and cooperation across 17 societies. Proceedings of the National Academy of Sciences, 114(48), 201712921. https://doi.org/10.1073/pnas.1712921114

Roof, W. C. (1976). Traditional religion in contemporary society: A theory of local-cosmopolitan plausibility. American Sociological Review, 41(2), 195-208. https://doi.org/10.2307/2094469

Roudometof, V. (2012). Cosmopolitanism and empirical social research: Some methodological issues of an emerging research agenda. In G. Delanty (Ed.), Routledge handbook of cosmopolitan studies (pp. 115-126). Routledge.

Saroglou, V. (2011). Believing, bonding, behaving, and belonging: The big four religious dimensions and cultural variation. Journal of Cross-Cultural Psychology, 42(8), 1320-1340. https://doi.org/10.1177/0022022111412267

Saroglou, V., \& Galand, P. (2004). Identities, values, and religion: A study among Muslim, other immigrant, and native Belgian young adults after the 9/11 attacks. Identity, 4(2), 97-132. https://doi.org/10.1207/s1532706xid0402_1

Saroglou, V., \& Hanique, B. (2006). Jewish identity, values, and religion in a globalized world: A study of late adolescents. Identity, 6(3), 231-249. https://doi.org/10.1207/s1532706xid0603_2

Saroglou, V., \& Mathijsen, F. (2007). Religion, multiple identities, and acculturation: A study of Muslim immigrants in Belgium. Archive for the Psychology of Religion, 29(1), 177-198. https://doi.org/10.1163/008467207X188757

Schumann, S., Boer, D., Hanke, K., \& Liu, J. H. (2019). Social media use and support for populist radical right parties: Assessing exposure and selection effects in a two wave panel study. Information, Communications, and Society, 1-20. https://doi.org/10.31234/osf.io/r2gav

Sibley, C. S., \& Liu, J. H. (2007). New Zealand = bicultural? Implicit and explicit associations between ethnicity and nationhood in the New Zealand context. European Journal of Social Psychology, 37(6), 1222-1243. https://doi.org/10. 1002/ejsp.459

Stark, R. (1997). The rise of Christianity: How the obscure, marginal Jesus movement became the dominant religious force in the western world in a few centuries. HarperCollins.

UNDP. (2015). Human development report 2015. http://hdr.undp.org/sites/default/files/2015_human_development_ report.pdf

Vandenberg, R. J., \& Lance, C. E. (2000). A review and synthesis of the measurement invariance literature: Suggestions, practices, and recommendations for organizational research. Organizational Research Methods, 3(1), 4-70. https:// doi.org/10.1177/109442810031002

Vertovec, S., \& Cohen, R. (2002). Conceiving cosmopolitanism: Theory, context and practice. Oxford University Press.

Warburton, E. (2016). Jokowi and the new developmentalism. Bulletin of Indonesian Economic Studies, 52(3), 297-320. https://doi.org/10.1080/00074918.2016.1249262

Wiktor, S., Liu, J. H., \& Bilewicz, M. (under review). Media of contempt: Social media consumption increases normativity of xenophobic verbal violence. International Journal of Conflict \& Violence.

Wilcox, C. (2018). Onward Christian soldiers? The religious right in American politics. Routledge.

Yeşilada, B. A., \& Noordijk, P. (2010). Changing values in Turkey: Religiosity and tolerance in comparative perspective. Turkish Studies, 11(1), 9-27. https://doi.org/10.1080/14683841003746999

Yilmaz, I., \& Bashirov, G. (2018). The AKP after 15 years: Emergence of Erdoganism in Turkey. Third World Quarterly, 39(9), 1812-1830. https://doi.org/10.1080/01436597.2018.1447371

Ysseldyk, R., Matheson, K., \& Anisman, H. (2010). Religiosity as identity: Toward an understanding of religion from a social identity perspective. Personality and Social Psychology Review, 14(1), 60-71. https://doi.org/10.1177/ 1088868309349693 